\title{
Evaluation of antimicrobial prophylaxis use and rate of surgical site infection in surgical ward of Wachemo University Nigist Eleni Mohammed Memorial Hospital, Southern Ethiopia: prospective cohort study
}

Bruke B. Billoro ${ }^{1,4^{*}}$, Mengistu H. Nunemo ${ }^{2}$ and Seid E. Gelan ${ }^{3}$

\begin{abstract}
Background: Surgical site infection (SSI) is the foremost infection in the overall patient population, affecting up to $66 \%$ of operated patients and with a frequency up to nine times more than in developed countries. This study aimed to determine the rate, associated factors of surgical site infection, and identification of causative agents and their antimicrobial susceptibility in surgical ward of Wachemo University Nigist Eleni Mohamed Memorial Hospital (WUNEMMH), Southern Ethiopia.
\end{abstract}

Method: Prospective cohort study involving 255 patients who underwent surgical procedure in WUNEMMH from January 1 to September 1, 2017. We extracted data from medical chart, operational and anesthesia note by direct observation and interviewer administered semi-structured questionnaire which was validated. We collected wound specimens and processed it based on standard operating procedure, and disc-diffusion antibiotic susceptibility test was done. Data analysis was done using SPSS version 22.0. Factors significantly associated were identified using logistic regression model at $P$-value $<0.05$ and $95 \% \mathrm{Cl}$.

Result: Forty-two patients (16.5\%) developed SSIs. The most causative organism of surgical site infection was Klebsiella pneumoniae (60\%).Ciprofloxacin and ceftriaxone were sensitive antibiotics. Surgery waiting time more than 7 days $[A R R=2.48(95 \% \mathrm{Cl}(1.28-4.79), P=0.007]$, Operation time more than $1 \mathrm{~h} .[\mathrm{ARR}=2.13(95 \% \mathrm{Cl}(1.18-3.86), P=0.012]$, and administering antibiotic before $1 \mathrm{~h}$ of operation [ARR $=5.05(95 \% \mathrm{Cl}(1.79-14.21), P=0.002]$, smoking $[\mathrm{ARR}=8.01$ (95\% Cl (2.15 29.84), $\mathrm{P}=0.002$ ] were independently associated with surgical site infections.

Conclusion: The rate of SSI was relatively high. Klebsiella pneumoniae was found to be the most causative agent for SSI. Organisms causing SSI were sensitive to commonly used antimicrobial agents in WUNEMMH.

Keywords: Risk factors, Surgical wound infection, Susceptibility, Prospective, Ethiopia

\footnotetext{
*Correspondence: 3b2005pharm@gmail.com; brukeB@wcu.edu.et 'Department of Pharmacy, College of Medicine and Health Sciences, Wachemo University, Hosanna, Ethiopia

${ }^{4}$ Department of Clinical Pharmacy, Near East University, Nicosia, Northern

Cyprus, Cyprus

Full list of author information is available at the end of the article
}

(c) The Author(s). 2019 Open Access This article is distributed under the terms of the Creative Commons Attribution 4.0 International License (http://creativecommons.org/licenses/by/4.0/), which permits unrestricted use, distribution, and reproduction in any medium, provided you give appropriate credit to the original author(s) and the source, provide a link to the Creative Commons license, and indicate if changes were made. The Creative Commons Public Domain Dedication waiver (http://creativecommons.org/publicdomain/zero/1.0/) applies to the data made available in this article, unless otherwise stated. 


\section{Background}

A surgical site infection (SSI) is an infection which happens within thirty days at the operative site if no graft is left in place or within ninety (90) days if an insert is left in place after the surgical operation. The surgical procedure determines the category of infection must appear [1]

SSIs are the third common hospital acquired infection which accounts $38 \%$ of all nosocomial infections according to center for disease control (CDC's) national nosocomial infection surveillance system [2].

In countries with limited resources, SSI is the foremost infection in the overall patient population, affecting up to $66 \%$ of operated patients and nine times more than in industrialized countries [3].

Increase hospital stays time, readmissions and additional use of antimicrobials which lead to antibiotic-resistant were seen by SSIs [4].On average, SSIs increased postoperative hospital stay by 6.5 to 11 days and 3.57 additional drug uses [2, 4]. SSI increased cost in England from $\$ 1,341-10,922$ per patient, in Europe $€ 3,985$ /day and in the USA $\$ 25,546$ per infection depending on surgery type and infection severity at institutional as well as national level $[5,6]$.

Study indicated that nearly $40-60 \%$ of SSIs can be prevented with the appropriate use of surgical antimicrobial prophylaxis (AMP) [7, 8]. Approximately $30-50 \%$ of antimicrobials used in hospitals are for surgical prophylaxis but $30-90 \%$ of them are used inappropriately $[9,10]$ which attribute for $16 \%$ of SSIs [8].

Antimicrobials are a serious matter and resources are in short supply to prevent rise of resistance and limit the degree of this problem in developing countries. Although pathogens resistivity has increased, unfortunately, no new antimicrobials that can manage this resistance have been introduced and are not expected in the future [11, 12]. World Health organization (WHO) described as resistance to antimicrobials has been a main threat to worldwide public health because there are few antimicrobials available to treat life-threatening infections in some cases [13].

Unnecessary extra costs, potential promotion of microbial resistance selection and a precious resource wastage in health care occur due to inappropriate use of AMP. Studies presented that the cost of inappropriate AMP is approximately 10 times higher than the values expected [14, 15].

Gram-positive cocci and gram-negative bacilli are major causative organisms of SSI as described by multi and single centered studies $[16,17]$.

Due to inadequate SSI surveillance programs in many of sub-sahara Africa, healthcare centers are unable to get an update on bacteria which is resistant to the antimicrobial [18]. In developing countries tests which would be used to isolate the organism and the correct antibiotic has limited accessibility and affordability [19].

Periodic surveillance and feedback to surgeons on the rate of SSIs and factors significantly associated can reduce up to $50 \%$ of SSIs rate according to $\mathrm{WHO}$ and other studies $[5,20]$.

Studies on rates of SSI, factors independently associated with SSI as well as on the causative agents and antibiotics susceptibility test are scarce in Ethiopia.

To our knowledge, studies focusing on SSI causing bacteria and their sensitivity pattern to antibiotics were not done in the study area.

Therefore, our study aimed to show the rate of SSI as well as factors associated with SSIs and characterize the susceptibility patterns of bacterial agents causing SSI at surgical ward department of WUNEMMH.

\section{Methods \\ Study area}

Conducted in surgical department of WUNEMMH which is government hospital.

\section{Study design and period}

A prospective cohort study in the surgical ward from January 1, 2017, to September 1, 2017, at WUNEMMH.

\section{Study population}

All patients who admitted for elective and emergency surgical procedures, and who fulfill eligibility criteria during the study period.

\section{Sample size}

Calculated using single population proportion formula with of 5\% and proportion for SSI rate is $19.1 \%$ [21]. By considering $10 \%$ contingency, total sample size would be 280 patients.

\section{Study procedures}

Patients who were not willing to participate, receiving antimicrobial during admission or stopped receiving within 48 hours before operation and patients with initial diagnosis suggestive of infection were excluded. Written consent was obtained and interviewer administered semi-structured questionnaire was used for socio-demographic characteristics.

Socio-demographic and patient-related factors were collected from patient's medical chart. Data on antimicrobials administration after operation and duration of administration were obtained from medication chart and direct observation.

Data were collected by three Nurses (BSc) using pretested data collection tool and the data collection was supervised daily by the research team. 
Wound classification was done using Center for Disease Prevention and Control (CDC) criteria for surgical site infections surveillance and WUNEMMH surgeons were responsible for diagnosing surgical patients' infection

\section{Specimen collection procedures}

Sterile swabs were used for collection of exudates from wounds of patients who develop SSI which transferred at room temperatures to the laboratory within $20 \mathrm{mi}-$ nutes. Chocolate, blood, and Mac-Conkey agar were used for inoculating swabs. We sited chocolate plate with other plates in a candle jam jar and keep warm at $35-37^{\circ} \mathrm{C}$ for $24-48$ hours. We report organisms by performing gram stain procedure on culture growth. An additional blood agar plate was inoculated anaerobically at $35-37^{\circ} \mathrm{C}$ for $48-72$ hours.

\section{Sensitivity pattern of antibiotics}

Disk diffusion test was performed for testing sensitivity [22]. They were exposed to gentamicin, erythromycin, ceftriaxone, ciprofoxacillin, chloramphenicol (CAF), cloxacillin, ampicillin, and tetracycline. We did not test for methicillin resistant Staphylococcus aureus (MRSA) and gram negatives which are extended-spectrum producers since this was not our study aim.

\section{Statistical analysis}

We used Epi-Data version 3.1 and analyzed using SPSS for window version 20.0. Frequency and percentages were used to describe socio-demographic, surgery-related factors, type of surgery and sensitivity of causative agents. Before running a multivariable binary logistic regression, multicollinearity between the independent variables was checked in linear regression by variance inflation factors (VIF). The model fitness for the variables was evaluated by the Hosmer-Lemeshow goodness of fit test. P-value of less than 0.05 was considered as independently associated in the multivariable analysis.

\section{Result}

\section{Social demographic factor}

Twenty-five patients out of 280 patients were excluded based on the exclusion criteria. The analysis was done on a total of 255 patients. 147 patients $(57.65 \%)$ were males and more than half patients were from rural area $150(58.8 \%)$. Nine patients $(3.5 \%)$ were obese with BMI > $=30 \mathrm{~kg} / \mathrm{m} 2$. Twelve patients $(4.7 \%)$ received blood transfusion preoperatively (Table 1 ).

\section{Surgery-related factor}

One hundred forty-four (56.5\%) surgical procedures were clean wound and $177(69.4 \%)$ surgical procedures
Table 1 Socio-demographic factors in surgical ward of WUNEMMH from January 1 to September 1, $2017(N=255)$

\begin{tabular}{llll}
\hline Variables & & Frequency & Percent \\
\hline Residence & Urban & 105 & 41.2 \\
& Rural & 150 & 58.8 \\
Cigarette smoking & No & 192 & 75.3 \\
& Yes & 63 & 24.7 \\
Gender & Female & 108 & 42.35 \\
& Male & 147 & 57.65 \\
Age categories in a year & $1-18$ & 63 & 24.7 \\
& $19-40$ & 111 & 43.5 \\
Obesity & $>40$ & 81 & 31.8 \\
Preoperative blood transfusion & BMI <30 kg/m2 & 246 & 96.5 \\
& BMI > =30 kg/m2 & 9 & 3.5 \\
Surgery waiting time & Yes & 243 & 95.3 \\
& $<=7$ days & 12 & 4.7 \\
ASA score & $>7$ days & 198 & 77.65 \\
& I & 66 & 22.35 \\
& II & 171 & 25.9 \\
& III & 18 & 7.1 \\
\hline
\end{tabular}

were elective. 225 (88.2\%) had no history of previous surgical procedure (Table 2).

\section{Surgery procedure type}

Caesarean section, $72(28.2 \%)$ was the leading procedure followed by appendectomy, 54(21.2\%), head and neck surgery, 32(12.5\%) (Table 3).

\section{Rate of SSI}

Out of 255 patients, 42(16.5\%) patients developed SSIs. Among patients who developed SSIs, 38 (90.47\%) patients developed SSIs in hospital.

We followed patients and reviewed charts daily before, during and after operation until the patients were

Table 2 Surgical related factors in the surgical ward of WUNEMMH from January 1 to September 1, $2017(N=255)$

\begin{tabular}{lll}
\hline Variables & Frequency & Percent \\
\hline Previous surgery & 30 & 11.8 \\
Yes & 225 & 88.2 \\
No & & \\
Wound class & 144 & 56.5 \\
Clean & 111 & 43.5 \\
Clean-contaminated & & \\
Surgical type & 177 & 69.4 \\
Elective & 78 & 30.6 \\
Emergency & & \\
\hline
\end{tabular}


Table 3 Surgical procedure done in the surgical ward of WUNEMMH from January 1 to September 1, 2017 ( $\mathrm{N}=255)$

\begin{tabular}{lll}
\hline Variables & Frequency & Percent \\
\hline Caesarean section & 72 & 28.2 \\
Appendectomy & 54 & 21.2 \\
Head and neck surgery & 32 & 12.5 \\
Genitourinary surgery & 30 & 11.8 \\
Hernia repair & 28 & 10.9 \\
Breast surgery & 21 & 8.2 \\
Hepato-biliary surgery & 15 & 5.9 \\
Lipoma excision & 3 & 1.2 \\
Total & 255 & 100.0 \\
\hline
\end{tabular}

discharged from the hospital and after discharge till 30 days since operation was done

\section{Etiological organisms for SSIs}

Klebsiella pneumonia was found to be the most common for $60.0 \%$ of isolates followed by Staphylococcus aureus (17.8\%), Escherichia colli (11.1\%) and Pseudomonas aeruginosa (11.1\%).

\section{Sensitivity of causative organisms}

Ceftriaxone was used as prophylactic antibiotic in study area. Susceptibility test to identified organisms were done in eight drugs. $35 \%$ of them had resistance to organisms which include ampicillin, tetracycline and erythromycin. The remaining $65 \%$ of drugs had different sensitivity patterns.

Klebsiella species were $88.9 \%$ susceptible to ciprofloxacin, ceftriaxone, and Pseudomonas aeruginosa was 100\% susceptible to both drugs. Klebsiella species and Pseudomonas aeruginosa showed different resistant pattern for gentamycin and chloramphenicol. Escherichia colli was found to be resistant organism from gram-negative.

Staphylococcus aureus was the only gram-positive isolate identified, and had sensitivity to ciprofloxacillin and cloxacillin. It was $100 \%$ sensitive to ceftriaxone and gentamycin but found to be resistant to chloramphenicol.

Ciprofloxacin and ceftriaxone had best sensitivity with P-values of 0.021 and 0.001 , respectively. Chloramphenicol was found to be resistant to both Gram-positive and Gram-negative organisms (Table 4).

\section{Factors associated with surgical site infection}

Surgery waiting time $>7$ days, Operation time $>1$ hours, administering AMP before 1 hour of operation, and smokers were factors independently associated with SSIs (Table 5).

Smokers were 8.01 times more likely to develop SSIs compared with non-smokers [ARR $=8.01$ (95\%CI $(2.15-$ 29.84)]. Moreover, Hospital stay more than 7 days preoperatively were likely to increase SSI by odd of 2.48 times compared with preoperative hospital stay less than 7 days $[$ ARR $=2.48(95 \%$ CI $(1.28-4.79)]$.

Patients with operation time more than 1 hour increased SSI by 2.13 times compared with patients whose operation finished within 1 hour $[\mathrm{ARR}=2.13(95 \% \mathrm{CI}$ (1.18-3.86)].

Administering antibiotic before 1 hour were likely to increase SSI by risk of 5.05 times more than those who did not get AMP administration within 1 hour $[\mathrm{ARR}=$ 5.05(95\% CI(1.79-14.21)] (Table 5).

Table 4 Organisms' sensitivity to antibiotics in the surgical ward of WUNEMMH from January 1 to September 1, 2017

\begin{tabular}{|c|c|c|c|c|c|c|}
\hline Sensitivity & klebsiella species. & Staphylococcus aureus & Pseudomonas & Escherichia colli & Total sensitivity & P-value \\
\hline \multicolumn{7}{|c|}{ chloramphenicol (CAF) } \\
\hline Resistant & $2(33.3)$ & $4(80)$ & $1(100)$ & $2(100)$ & 9 & \multirow[t]{2}{*}{0.124} \\
\hline Sensitivity & $4(66.6)$ & $1(20)$ & 0 & 0 & 5 & \\
\hline \multicolumn{7}{|l|}{ gentamycin } \\
\hline Resistant & $3(33.3)$ & 0 & $1(100)$ & $1(50)$ & 5 & \multirow[t]{2}{*}{0.135} \\
\hline Sensitivity & $6(66.6)$ & $3(100)$ & 0 & $1(50)$ & 10 & \\
\hline \multicolumn{7}{|l|}{ ciprofloxacillin } \\
\hline Resistant & $1(11.1)$ & $1(25)$ & 0 & $2(100)$ & 4 & \multirow[t]{2}{*}{0.021} \\
\hline Sensitivity & $8(88.9)$ & $3(75)$ & $2(100)$ & 0 & 13 & \\
\hline \multicolumn{7}{|l|}{ ceftriaxone } \\
\hline Resistant & $1(11.1)$ & 0 & 0 & $2(100)$ & 3 & \multirow[t]{2}{*}{0.001} \\
\hline Sensitivity & $8(88.9)$ & $3(100)$ & $2(100)$ & 0 & 13 & \\
\hline \multicolumn{7}{|l|}{ cloxacillin } \\
\hline Resistant & & $1(25)$ & & & & \\
\hline Sensitivity & & $3(75)$ & & & & \\
\hline
\end{tabular}


Table 5 Results of binary and multivariable logistic analysis indicating factors significantly associated with SSI in the surgical ward of WUNEMMH from January 1 to September 1, $2017(N=255)$

\begin{tabular}{|c|c|c|c|c|c|c|}
\hline \multirow[t]{2}{*}{ Characteristics } & & \multicolumn{2}{|c|}{ Surgical site infection } & \multirow[t]{2}{*}{$\mathrm{RR}(95 \% \mathrm{Cl})$} & \multirow[t]{2}{*}{$\operatorname{ARR}(95 \% \mathrm{Cl})$} & \multirow{2}{*}{$\begin{array}{l}P \text { - } \\
\text { value }\end{array}$} \\
\hline & & $\begin{array}{l}\text { Yes N (\%) } \\
42(16.5 \%)\end{array}$ & $\begin{array}{l}\text { No N (\%) } \\
213(83.5 \%)\end{array}$ & & & \\
\hline \multirow[t]{2}{*}{ Surgery waiting time } & $>7$ days & $33(55 \%)$ & $27(45 \%)$ & $1.92(1.12-3.31)$ & $2.48(1.28-4.79)$ & $0.007^{*}$ \\
\hline & $<=7$ days & $9(4.6 \%)$ & $186(95.4 \%)$ & & 1 & \\
\hline \multirow[t]{2}{*}{ Smokers } & Yes & $18(30 \%)$ & $42(70 \%)$ & $7.55(2.50-22.78)$ & $8.01(2.15-29.84)$ & $0.002^{*}$ \\
\hline & No & $24(12.3)$ & $171(87.7 \%)$ & & 1 & \\
\hline \multirow[t]{2}{*}{ Operation time } & $>1 \mathrm{~h}$ & $33(32.4 \%)$ & $69(67.6 \%)$ & $2.57(1.56-4.23)$ & $2.13(1.18-3.86)$ & $0.012^{*}$ \\
\hline & $<=1 \mathrm{~h}$ & $9(5.9 \%)$ & $144(94.1 \%)$ & & 1 & \\
\hline \multirow[t]{2}{*}{ Administering antibiotic before $1 \mathrm{~h}$ of operation } & $>1 \mathrm{~h}$ & $30(20 \%)$ & $120(80 \%)$ & $5.27(2.05-13.54)$ & $5.05(1.79-14.21)$ & $0.002^{*}$ \\
\hline & $<=1 \mathrm{~h}$ & $12(11.4 \%)$ & $93(88.6 \%)$ & & 1 & \\
\hline \multirow[t]{2}{*}{ Residence } & Rural & 33 (22.4\%) & $114(77.6 \%)$ & 1.57 (0.689-6.786) & $1.53(0.124-3.740)$ & 0.691 \\
\hline & Urban & $9(8.3 \%)$ & 99 (91.7) & & 1 & \\
\hline \multirow[t]{3}{*}{ Age in year } & $1-18$ & $6(8.7 \%)$ & $63(91.3 \%)$ & $0.79(0.305-5.346)$ & $1.71(0.206-8.723)$ & 0.849 \\
\hline & $19-40$ & $9(8.3 \%)$ & 99 (91.7\%) & & 1 & \\
\hline & $>40$ & 27 (34.6\%) & $51(65.4 \%)$ & $7.11(1.47-15.022)$ & $7.72(8.46-40.810)$ & \\
\hline \multirow[t]{2}{*}{ ASA Score } & $>1$ & 39 (20.6\%) & $150(79.4 \%)$ & $6.09(0.607-29.16)$ & $6.27(0.52-15.501)$ & 0.076 \\
\hline & $<=1$ & $3(4.5 \%)$ & $63(95.5 \%)$ & & 1 & \\
\hline \multirow[t]{2}{*}{ Co-morbidity } & Present & $6(28.6 \%)$ & $15(71.4 \%)$ & $3.51(0.545-8.96)$ & $1.39(0.154-16.11)$ & 0.358 \\
\hline & Absent & 36 (15.4\%) & $198(84.6 \%)$ & & 1 & \\
\hline \multirow[t]{2}{*}{ Previous surgery } & Yes & $12(40 \%)$ & $18(60 \%)$ & $2.23(1.540-15.62)$ & $7.64(0.639-34.04)$ & 0.678 \\
\hline & No & 30 (13.3\%) & 195 (86.7\%) & & 1 & \\
\hline \multirow[t]{2}{*}{ Wound class } & Clean-contaminated & 27 (24.3\%) & $84(75.7 \%)$ & 1.52 (0.194-1.388) & $3.54(0.70-4.698)$ & 0.185 \\
\hline & Clean & 15 (10.4\%) & $129(89.6 \%)$ & & 1 & \\
\hline
\end{tabular}

RR Relative risk, ARR Adjusted relative risk

*statistically significant

\section{Discussion}

Out of 255 patients who underwent surgical procedure, 42 patients developed SSIs which contribute to the overall rate of $16.5 \%$. This was consistent with similar studies done in Ethiopia 19.1\% [21], Uganda 16.4\% [23] and Nigeria $20.3 \%$ [24]. But, it is relatively less compared to study done in Tanzania 26\% [25]. This difference might be for the reason that our study included only wounds which are clean and clean-contaminated while other studies included contaminated and dirty wound. The finding was higher compared with studies done in USA 7.2\% [26] and Saudi Arabia $6.8 \%$ [27]. The difference might be due to modern surgical techniques, surgery rooms and sufficient trained professionals in developed countries.

Smoking contributes to the development of SSI by causing vasoconstriction which results in tissue hypoxia and hypovolemia locally as well as systemically which delays the healing progress, an environment conducive to SSI. In our study patients who smokes were 8.01 times more likely to develop SSIs compared with non-smokers with [ARR $=8.01$ (95\% CI (2.15-29.84), $\mathrm{P}=0.002]$. This study is in support of study done in Tanzania [25].
Waiting time for surgery at hospital exposes the patients to contamination or colonization by pathogens which will contribute to the occurrence of SSI [28]. Also patients with long stay in hospital before surgery were sicker or had higher comorbidities that increase their risk for SSI. Hospital stay more than 7 days preoperatively was likely to increase SSIs by risk of 2.48 times compared with preoperative hospital stay less than 7 days, $[A R R=2.48$ (95\% CI (1.28-4.79), P= 0.007]. Similar to our finding, study done in Egypt showed that patients who underwent operation within 2 days of admission decreased risk of SSI more than those whose operation done after 2 days $(\mathrm{P}=0.0034)$ [29]. This confirms that as the duration of hospital stay preoperatively gets shorten, it minimize rate of SSIs.

In our study, the rate of SSIs were $10.4 \%$ and $24.3 \%$ in the clean wound and in the clean-contaminated wound respectively. The finding was in contrast with study showed in Tanzania which indicated the rate as clean (63\%) and clean-contaminated (33.7\%) [25]. As well as in study conducted in Egypt indicated that $57 \%$ and $20 \%$ were clean and clean-contaminated wounds 
respectively [29]. Similar findings have been documented in India where the rate of SSI was higher in clean-contaminated wound (22.8\%) compared to wound which are clean (15.1\%) [28]. Also in study done in Sudan the rate of SSI was higher in clean contaminated (9.5\%) relative to clean wound (8\%) [30]. The lesser rate of SSIs in clean wound in our study might be due to close precaution was taken to clean wound and might also be due to rational use of ceftriaxone for the most clean wound, which might result in sensitive strains in the clean wound as indicated [31] and also our study confirms that ceftriaxone is highly sensitive to suspected organisms in clean wound.

The prolonged operation is an independent factor for SSIs in other study because of higher risk for infection due to incision of the operation site [32]. It also increases the extent of tissue trauma due to an extensive surgical procedure, long duration of anesthesia effect, increased blood loss and also decrease surgical antimicrobial prophylaxis concentration at tissue level which all increases the risk of SSIs $[25,28]$. In our study, patients with duration of operation more than 1 hour were 2.13 times more likely to develop SSI compared to patients whose operation completed within 1 hour, $[\mathrm{ARR}=2.13$ (95\% CI $(1.18-3.86), \mathrm{P}=0.012]$ which was in line with other study [33].

Administering AMP before 1 hour was observed to be an independent factor associated with SSIs in previous study [34]. In this study, AMP administration before 1 hour increased SSIs risk by 5.05 times compared with administration of first dose of surgical antimicrobial prophylaxis within 1 hour of skin incision $[\mathrm{ARR}=5.05$ (95\% CI(1.79-14.21),P=0.002]. Antimicrobials concentration is not sufficient enough at the action site in tissue, as well as in serum to avoid the contamination during operation until wound closure if the first dose of antimicrobial was administered 1 hour earlier. One study indicated that low antibiotic concentration in tissue at the time of wound closure was an independent factor for the development of SSIs [35].

Concerning to the causative agents, common cause of SSI were Klebsiella pneumoniae followed by Staphylococcus aureus, Escherichia colli and Pseudomonas aeruginosa. Most of the operations were caesarean section (CS) and appendectomy which were either clean or clean-contaminated. Our study suggested that the probable reason for the organisms to cause SSI was the spillage of this organism from the GIT. The aerobic-anaerobic organisms closely similar with the normal endogenous flora of the operated organ like clean-contaminated surgery of CS constitutes the most identified bacterial agents.

Gram-negative bacilli are the most common aerobic bacterial agents causing SSIs in CS patients and our finding showed that the predominant etiology was Klebsiella species.

The finding of our study is concordant with other studies done Nigeria, Uganda, Tanzania [36-39] which showed that gastrointestinal tract (appendectomy) is a natural habitat for Klebsiella pneumonia's.

In our study resistance to antibiotics were from $11.1 \%$ for Klebsiella to $100 \%$ (Escherichia colli). A similar finding has been documented with other studies conducted in Mbarara, Mulago and Tanzania [37-39].

In our study Klebsiella pneumoniae has high sensitivity to both ciprofloxacin and ceftriaxone but was resistant to ampicillin, tetracycline, and erythromycin. In line with our study, study conducted in Kenya showed that Klebsiella's resistant to ceftriaxone [40] and resistance to chloramphenicol was also reported in Uganda [41].

Our study showed that ciprofloxacin, ceftriaxone, cloxacillin, and gentamycin were sensitive to Staphylococcus aureus, but were resistant to erythromycin, chloramphenicol, and ampicillin. This was in line with a study done in Uganda [41]. The finding for ceftriaxone in our study is surprisingly indicated high sensitivity against both Gram-negative and Gram-positive organisms since the drug is frequently prescribed to almost all patients who underwent operation.

The result of this study will provide information for surgeons, working organizations like Non-governmental organizations (NGOs) in health care system of WUNEMMH as well as in national and international level to decrease the rate of SSI and related complications with SSIs.

\section{Limitation}

Professionals' related variables, antiseptics used, surgical equipment sterilization methods and anesthesia type were not included due to resources shortage.

Despite limitation, the study provides baseline information on rate of SSI, associated factors of surgical site infection as well as on the causative agents and their antimicrobial susceptibility in the surgical ward of WUNEMMH.

\section{Conclusion}

The rate of SSIs was $16.5 \%$ which was lower compared with some developing countries and higher relative to reports from developed countries. Klebsiella pneumonia found to cause the majority of SSI. Ceftriaxone and ciprofloxacin were sensitive antibiotics.

Surgery waiting time more than 7 days, smokers, administrating antibiotic before 1 hour and operation time more than 1 hour were independently associated with SSIs.

Antimicrobial resistance is one of world problem, which results partly due to unnecessarily administration 
of antibiotic for long period so administration of surgical AMP for long time should be avoided.

It becomes imperative, therefore, to know local antibiotic sensitivity patterns existing in a hospital to plan appropriate antibiotic policy.

In addition, periodic surveillance on rate of SSI, associated factors of surgical site infection, causative agents, and their antimicrobial susceptibility will decrease the rate.

A surveillance system for SSI with feedback of proper data to surgeons and hospital authorities is highly recommended to reduce SSI rate in WUNEMMH.

\section{Acknowledgements}

The author would like to express due appreciation for Wachemo University, for providing us different reference materials and financial support. We are also grateful to WUNEMMH surgeons and staffs, for allowing us to access patients' data.

\section{Funding}

The study was supported by research grant from Wachemo University [Hosanna, Ethiopia]. The funders had no role in the design, collection, investigation and explanation of data and in preparing the manuscript.

\section{Availability of data and materials}

The datasets used and/or analyzed during the current study will be made available from the corresponding author on reasonable request.

\section{Authors' contributions}

BB: collect data, analyzed, and drafted the manuscript. $\mathrm{MH}$ : designed study and reviewed it critically for intellectual content. SE: finalized study design and coordinated implementation. All authors read and approved the final manuscript.

\section{Ethics approval and consent to participate}

Ethical clearance was obtained from Wachemo University ethical review committee and official permission letter was obtained from Wachemo University Nigist Eleni Mohamed Memorial Hospital administrators to conduct the study. Written informed consent was obtained from each study participant before data collection and documented in prepared format. Privacy of the data was also assured and collected anonymously.

\section{Consent for publication}

Not applicable.

\section{Competing interests}

The authors declare that they have no competing interests.

\section{Publisher's Note}

Springer Nature remains neutral with regard to jurisdictional claims in published maps and institutional affiliations.

\section{Author details \\ 'Department of Pharmacy, College of Medicine and Health Sciences, Wachemo University, Hosanna, Ethiopia. '2Department of Public Health, College of Medicine and Health Sciences, Wachemo University, Hosanna, Ethiopia. ${ }^{3}$ Ethiopian Biotechnology Institute, Addis Ababa, Ethiopia. ${ }^{4}$ Department of Clinical Pharmacy, Near East University, Nicosia, Northern Cyprus, Cyprus.}

Received: 13 June 2018 Accepted: 11 March 2019 Published online: 02 April 2019

\section{References}

1. Bruce J, Russel EM, Mollison J. The measurement and monitoring of surgical adverse events. Health Technol Assess. 2001;5:13-28.
2. Ezechi OC, Fasuba OB, Dare FO. Socioeconomic barrier to safe motherhood among booked patients in rural Nigerian communities. J Obstet Gynaecol. 2000;20(1):32-4.

3. Singh $R$, Singla $P$, Chaudhary U. Surgical site infections: classification, risk factors, pathogenesis and preventive management. Int J Pharm Res Heal Sci. 2014:2:203-14.

4. Gagliardi AR, Fenech D, Eskicioglu C, Nathens AB, McLeod R. Factors influencing antibiotic prophylaxis for surgical site infection prevention in general surgery: a review of the literature. Can J Surg. 2009;52(6):481.

5. Ernesto C, Starling F, Horizonte B. Applicability of the national nosocomial infections surveillance system risk index for the prediction of surgical site infections: a review. Braz J Infect Dis. 2007;11(1):134-41.

6. Fan $Y$, Wei Z, Wang W, Tan L, Jiang H, Tian L, Cao Y, Nie S. The incidence and distribution of surgical site infection in mainland China: a meta-analysis of 84 prospective observational studies. Sci Rep. 2014;4:6783.

7. Bratzler DW, Dellinger EP, Olsen KM, Perl TM, Auwaerter PG, Bolon MK, Fish DN Napolitano LM, Sawyer RG, Slain D, Steinberg JP. Clinical practice guidelines for antimicrobial prophylaxis in surgery. Surg Infect. 2013;14(1):73-156.

8. CDC. Surgical infection prevention (SIP) collaborative problem statement; 2002. p. 1-16.

9. Burke JP. Maximizing appropriate antibiotic prophylaxis for surgical patients: an update from LDS hospital, Salt Lake City. Clin Infect Dis. 2001;33(Suppl 2):S78-83.

10. Cusini A, Rampini SK, Bansal V, Ledergerber B, Kuster SP, Ruef C, Weber R. Different patterns of inappropriate antimicrobial use in surgical and medical units at a tertiary care hospital in Switzerland: a prevalence survey. PLoS One. 2010;5(11):e14011.

11. Brand AM. Therapeutic properties of the lantibiotic nisin F (Doctoral dissertation, Stellenbosch: Stellenbosch University).

12. Apisarnthanarak A, Danchaivijitr S, Bailey TC, Fraser VJ. Inappropriate antibiotic use in a tertiary care center in Thailand: an incidence study and review of experience in Thailand. Infect Control Hosp Epidemiol. 2006;27(4):416-20.

13. World Health Organization. Antimicrobial resistance: global report on surveillance: World Health Organization; 2014.

14. Schmitt C, Lacerda RA, Padoveze MC, Turrini RN. Applying validated quality indicators to surgical antibiotic prophylaxis in a Brazilian hospital: learning what should be learned. Am J Infect Control. 2012:40(10):960-2.

15. Hatam N, Askarian M, Moravveji AR, Assadian O. Economic burden of inappropriate antibiotic use for prophylactic purpose in Shiraz, Iran. Iran Red Crescent Med J. 2011;13(4):234-8.

16. Anderson DJ, Sexton DJ, Kanafani ZA, Auten G, Kaye KS. Severe surgical site infection in community hospitals: epidemiology, key procedures, and the changing prevalence of methicillin-resistant Staphylococcus aureus. Infect Control Hosp Epidemiol. 2007;28(9):1047-53.

17. Cantlon CA, Stemper ME, Schwan WR, Hoffman MA, Qutaishat SS. Significant pathogens isolated from surgical site infections at a community hospital in the Midwest. Am J Infect Control. 2006;34(8):526-9.

18. Aiken AM, Karuri DM, Wanyoro AK, Macleod J. Interventional studies for preventing surgical site infections in sub-Saharan Africa-a systematic review. Int J Surg. 2012;10(5):242-9.

19. Byarugaba DK. Antimicrobial resistance in developing countries and responsible risk factors. Int J Antimicrob Agents. 2004;24(2):105-10.

20. Safety WP, World Health Organization. WHO guidelines for safe surgery: 2009: safe surgery saves lives. Geneva: World Health Organization; 2009.

21. Laloto TL, Gemeda DH, Abdella SH. Incidence and predictors of surgical site infection in Ethiopia: prospective cohort. BMC Infect Dis. 2017:17(1):119.

22. Bauer AW, Kirby WM, Sherris JC, Turck M. Antibiotic susceptibility testing by a standardized single disk method. Am J Clin Pathol. 1966;45(4):493-6.

23. Lubega A, Joel B, Justina Lucy $N$. Incidence and etiology of surgical site infections among emergency postoperative patients in mbarara regional referral hospital, South Western Uganda. Surg Res Pract. 2017;2017:6365172.

24. Nwankwo EO, Ibeh IN, Enabulele OI. Incidence and risk factors of surgical site infection in a tertiary health institution in Kano, northwestern Nigeria. Int J Infect Control. 2012;8(4):8-13.

25. Mawalla B, Mshana SE, Chalya PL, Imirzalioglu C, Mahalu W. Predictors of surgical site infections among patients undergoing major surgery at Bugando medical Centre in Northwestern Tanzania. BMC Surg. 2011;11(1):21.

26. Garey KW, Dao T, Chen H, Amrutkar P, Kumar N, Reiter M, Gentry LO. Timing of vancomycin prophylaxis for cardiac surgery patients and the risk of surgical site infections. J Antimicrob Chemother. 2006;58(3):645-50.

27. Khairy GA, Kambal AM, Al-Dohayan AA, Al-Shehri MY, Zubaidi AM, Al-Naami MY, AISaif FA, Al-Obaid OA, Al-Saif AA, El-Farouk OY, Al-Abdulkarim AA. 
Surgical site infection in a teaching hospital: a prospective study. J Taibah Univ Med Sci. 2011;6(2):114-20.

28. Banashankari G S, Rudresh H K, Harsha SS. An overview of surgical site infections: an insight into the prevalence, etiology and predisposing factors. Valley Int J 204AD; 1(9):493-499.

29. Wassef MA, Hussein A, El-Sherif RH. A prospective surveillance of surgical site infections: study for efficacy of preoperative antibiotic prophylaxis. Afr J Microbiol Res. 2012;6(12):3072-8.

30. Miliani K, L'hériteau F, Astagneau P, INCISO Network Study Group. Noncompliance with recommendations for the practice of antibiotic prophylaxis and risk of surgical site infection: results of a multilevel analysis from the INCISO surveillance network. J Antimicrob Chemother. 2009;64(6):1307-15.

31. Guta M, Aragaw K, Merid Y. Bacteria from infected surgical wounds and their antimicrobial resistance in Hawassa University referral teaching hospital, southern Ethiopia. Afr J Microbiol Res. 2014;8(11):1118-24.

32. Mangram AJ, Horan TC, Pearson ML, Silver LC, Jarvis WR. Hospital infection control practices advisory committee. Guideline for prevention of surgical site infection, 1999. Infect Control Hosp Epidemiol. 1999;20(4):247-80.

33. Elbur Al, Yousif M, Elsayed A, AbdelRahman M. Prevalence and predictors of wound infection in elective clean and clean/contaminated surgery in Khartoum teaching hospital, Sudan. Int J Infect Control. 2012;8(4):1-0.

34. Garey KW, Dao T, Chen H, Amrutkar P, Kumar N, Reiter M, et al. Timing of vancomycin prophylaxis for cardiac surgery patients and the risk of surgical site infections. J Antimicrobial Chemother. 2006;58:645-50.

35. Zelenitsky SA, Ariano RE, Harding GK, Silverman RE. Antibiotic pharmacodynamics in surgical prophylaxis: an association between intraoperative antibiotic concentrations and efficacy. Antimicrob Agents Chemother. 2002:46(9):3026-30.

36. Akinkunmi EO, Adesunkanmi AR, Lamikanra A. Pattern of pathogens from surgical wound infections in a Nigerian hospital and their antimicrobial susceptibility profiles. Afr Health Sci. 2014;14(4):802-9.

37. Seni J, Najjuka CF, Kateete DP, Makobore P, Joloba ML, Kajumbula H, Kapesa A, Bwanga F. Antimicrobial resistance in hospitalized surgical patients: a silently emerging public health concern in Uganda. BMC Res Notes. 2013;6(1):298.

38. Seni J, Bwanga F, Najjuka CF, Makobore P, Okee M, Mshana SE, Kidenya BR, Joloba ML, Kateete DP. Molecular characterization of staphylococcus aureus from patients with surgical site infections at Mulago Hospital in Kampala, Uganda. PLoS One. 2013;8(6):e66153.

39. Manyahi J, Matee MI, Majigo M, Moyo S, Mshana SE, Lyamuya EF. Predominance of multi-drug resistant bacterial pathogens causing surgical site infections in Muhimbili National Hospital, Tanzania. BMC Res Notes. 2014;7(1):500.

40. O. Okello S, R. Kuremu T, Ayumba BR, Ruto E, Otieno VO. Etiology and antimicrobial susceptibility of surgical site infections at Moi teaching and referral hospital, Eldoret-Kenya. Int Ann Med. 2018;2(4).

41. Anguzu JR, Olila D. Drug sensitivity patterns of bacterial isolates from septic post-operative wounds in a regional referral hospital in Uganda. Afr Health Sci. 2007;7(3).

Ready to submit your research? Choose BMC and benefit from:

- fast, convenient online submission

- thorough peer review by experienced researchers in your field

- rapid publication on acceptance

- support for research data, including large and complex data types

- gold Open Access which fosters wider collaboration and increased citations

- maximum visibility for your research: over $100 \mathrm{M}$ website views per year

At $\mathrm{BMC}$, research is always in progress.

Learn more biomedcentral.com/submissions 